(1)

GEORGE FOX

UNIVERSITY

Digital Commons @ George Fox University

Faculty Publications - Biomedical, Mechanical, and Civil Engineering

Department of Biomedical, Mechanical, and Civil Engineering

2008

\title{
The Role of Diffusive Transport on Low and Intermediate Temperature Hydrocarbon Oxidation: Numerical Simulations using the Wang-Mou Mechanism
}

\author{
Howard Pearlman \\ Drexel University \\ Michael R. Foster \\ George Fox University, mfoster@georgefox.edu
}

Follow this and additional works at: https://digitalcommons.georgefox.edu/mece_fac

Part of the Heat Transfer, Combustion Commons, Propulsion and Power Commons, and the Space Vehicles Commons

\section{Recommended Citation}

Pearlman, Howard and Foster, Michael R., "The Role of Diffusive Transport on Low and Intermediate Temperature Hydrocarbon Oxidation: Numerical Simulations using the Wang-Mou Mechanism" (2008). Faculty Publications - Biomedical, Mechanical, and Civil Engineering. 27.

https://digitalcommons.georgefox.edu/mece_fac/27

This Article is brought to you for free and open access by the Department of Biomedical, Mechanical, and Civil Engineering at Digital Commons @ George Fox University. It has been accepted for inclusion in Faculty Publications - Biomedical, Mechanical, and Civil Engineering by an authorized administrator of Digital Commons @ George Fox University. For more information, please contact arolfe@georgefox.edu. 
THE ROLE OF DIFFUSIVE TRANSPORT ON LOW AND INTERMEDIATE TEMPERATURE HYDROCARBON OXIDATION: NUMERICAL SIMULATIONS USING THE WANG-MOU MECHANISM

\section{Howard Pearlman ${ }^{1, *}$ and Michael Foster ${ }^{2}$}

${ }^{1}$ Drexel University, Department of Mechanical Engineering and Mechanics, Philadelphia, Pennsylvania, USA

${ }^{2}$ George Fox University, Department of Mathematics, Computer Science and Engineering, Newberg, Oregon, USA

The spatio-temporal temperature and species concentration distributions associated with low and intermediate temperature hydrocarbon oxidation are computed using a global thermokinetic scheme augmented with diffusive transport. The scheme used for the computations was proposed by Wang and Mou and is extended to include diffusion of species and heat. The conservation equations for species and energy are then derived and solved for a one-dimensional and an axisymmetric, spherical domain for temperatures ranging from 540 to $660 \mathrm{~K}$ at subatmospheric pressures. The predictions are then used to develop ignition diagrams for different Lewis (Le) numbers. Increasing Le is found to promote oscillatory cool flames and two-stage ignition in the one-dimensional model, while the ratio of the mass diffusivity of the parent fuel to that associated with the autocatalytic chain carrier has a negligible effect on the structure of the ignition diagrams. In the spherical model, oscillatory cool flames and two-stage ignition were also predicted albeit at lower values of the Le.

Keywords: Autoignition; Cool flames; Microgravity; Thermokinetic oscillations; Wang-Mou model

\section{INTRODUCTION}

Cool flame, two-stage ignition, and single-stage ignition experiments have been conducted in closed, static reactors at reduced-gravity to explore the reactive-diffusive structure that develops in the absence of buoyant convection (Pearlman, 2000; Foster and Pearlman, 2006). Such experiments are not possible at terrestrial conditions since the pressure and the vessel size cannot be reduced to the extent needed to decrease the Rayleigh number $(\mathrm{Ra})$ below the critical value associated with the onset of buoyant convection $\left(\mathrm{Ra}_{\mathrm{cr}} \approx 600\right)$ (Yang and Gray, 1969b; Barnard and Harwood, 1974; Fairlie et al., 2000; Pearlman, 2000; Cardoso et al., 2004a,b; Campbell et al., 2006; Foster and Pearlman, 2006). As a result, static reactor cool

Special thanks are extended to Richard Chapek at NASA GRC for supporting the microgravity experiments and Yoohanon George at Drexel University for performing some of the numerical computations. This work was funded by NASA under grant NCC3-1006. The authors also acknowledge financial support for MF through the NSF Graduate Research Fellowship Program.

*Address correspondence to hp37@drexel.edu 
flame and ignition experiments at terrestrial conditions are inherently multi-dimensional due to buoyant convection. To suppress buoyancy and isolate the effects of diffusion on the temperature and species concentration distributions, NASA a free-fall facility has been used to effectively reduce gravity and thereby reduce the associated $\mathrm{Ra}(\mathrm{Ra} \sim \mathrm{g})$.

To model the reactive-diffusive structure of cool flames and ignitions in closed reactors, models of various fidelities have been reported; these models have been based on the two-step Sal'nikov mechanism (Cardoso et al., 2004a,b; Campbell et al., 2006), the Gray-Yang mechanism (Yang and Gray, 1969a, 1969b; Fairlie et al., 2000), and a reduced propane oxidation mechanism (58 species, 378 reactions) (Fairlie et al., 2004). The Sal'nikov model is the simplest, includes thermal feedback, and has been used successfully to predict the temperature and the species concentration distributions associated with low temperature oxidation and cool flames. To compliment the Sal'nikov model, the Gray-Yang model was also considered because it includes both thermal and chemical feedback, both of which are important in low and intermediate temperature hydrocarbon chemistry. By far, the most comprehensive model to date that includes species and thermal diffusion is the propane model referenced above. These models predict a nearly parabolic temperature distribution during the early stages of development with a peak temperature at the center, similar to the temperature profiles predicted by classical conductive thermal ignition theories. As the reaction continues, the profiles tend to develop steeper temperature gradients near the wall, flatten out in the center, and then eventually cool to the original wall temperature.

To further explore the reactive-diffusive structure of cool flames and ignitions within the framework of a global mechanism, this study explores the Wang and Mou thermokinetic scheme (Wang and Mou, 1985; Liang et al., 2003) augmented with diffusive fluxes of heat and species. The scheme is based on the original Gray-Yang model with the addition of a high-temperature branching step. Moreover, the Wang-Mou model has been successfully shown to capture modes of slow reaction, oscillatory cool flames, oscillatory two-stage ignitions, complex oscillations and high-temperature ignition in a zero-dimensional CSTR (Wang and Mou, 1985).

This article begins with a description of the model and a new non-dimensionalization based on a diffusion time. It is then numerically applied to a one-dimensional and a spherically-symmetric domain. Representative temperature and species concentration distributions are computed and used to develop ignition diagrams. The effect of variable Lewis number (Le, ratio of thermal diffusivity of the mixture to mass diffusivity of the parent fuel) on the predicted temperature and species concentration distributions and ignition diagrams is also considered. In a complimentary experimental study (Pearlman and Foster, 2007), free-fall, closed reactor experiments were conducted using an equimolar $n-\mathrm{C}_{4} \mathrm{H}_{10}+\mathrm{O}_{2}$ premixture and the associated pressure histories and temperature profiles were reported and used to develop an ignition diagram.

\section{METHODOLOGY}

A reactive-diffusive model is developed based on Wang-Mou global mechanism, which has five, irreversible steps and includes initiation (I), high-temperature branching (II), low-temperature branching (III), high-temperature termination (IV), 
and low-temperature termination (V) steps (Wang and Mou, 1985; Liang et al., 2003). The scheme has two variables, "y" and "x." Species "y" represents the fuel and oxygen and species "x" represents an autocatalytic chain carrier. $S_{1}$ and $S_{2}$ represent terminal product species.

$$
\begin{gathered}
y \rightarrow x \\
x+y \rightarrow 2 x \\
x \rightarrow 2 x \\
x \rightarrow S_{1} \\
x \rightarrow S_{2}
\end{gathered}
$$

The reaction rates, $\left(\overline{\mathrm{k}}_{\mathrm{i}}\right)$ and their respective pre-exponential factors $\left(\mathrm{A}_{\mathrm{i}}\right)$, activation energies $\left(E_{i}\right)$, and associated heat releases $\left(\bar{h}_{i}\right)$ are taken from reference (Wang and Mou, 1985) and summarized in Table 1. As in previous studies, $E_{2}>E_{1}>E_{4}>E_{3}>E_{5}$. Note that the rate parameters were tuned for acetaldehyde oxidation. As mentioned, the model has been shown to successfully predict modes of slow reaction, oscillatory cool flames, two-stage ignitions, complex oscillations and high-temperature ignition, which are qualitatively similar to those observed in $\mathrm{C}_{3}$ and higher molecular weight alkanes, including n-butane, which is reported in a separate experimental study (Pearlman and Foster, 2008).

The $\mathrm{x}$ and $\mathrm{y}$ species conservation equations including diffusive fluxes of species can be written as:

$$
\frac{\partial \overline{\mathrm{x}}}{\partial \overline{\mathrm{t}}}=\overline{\mathrm{k}}_{1} \overline{\mathrm{y}}+\overline{\mathrm{k}}_{2} \overline{\mathrm{x}} \overline{\mathrm{y}}-\left(-\overline{\mathrm{k}}_{3}+\overline{\mathrm{k}}_{4}+\overline{\mathrm{k}}_{5}\right) \overline{\mathrm{x}}+D_{\mathrm{X}} \bar{\nabla}^{2} \overline{\mathrm{x}}
$$

and

$$
\frac{\partial \overline{\mathrm{y}}}{\partial \overline{\mathrm{t}}}=-\overline{\mathrm{k}}_{1} \overline{\mathrm{y}}-\overline{\mathrm{k}}_{2} \overline{\mathrm{x}} \overline{\mathrm{y}}+D_{\mathrm{Y}} \bar{\nabla}^{2} \overline{\mathrm{y}}
$$

where $\bar{x}$ and $\bar{y}$ are the concentrations of species $x$ and $y\left(\mathrm{~mol} / \mathrm{cm}^{3}\right), D_{X}$ and $D_{Y}$ are the mass diffusivities of species $x$ and $y\left(\mathrm{~cm}^{2} / \mathrm{s}\right)$, and $\bar{t}$ is the time (s). Quantities indicated with bars are dimensional quantities.

Table 1 Summary of Wang-Mou global model

\begin{tabular}{lccc}
\hline Reaction rate, $\overline{\mathrm{k}}_{\mathrm{i}}$ & $\begin{array}{c}\text { Pre-exponential } \\
\text { factor, } \mathrm{A}_{\mathrm{i}}\end{array}$ & $\begin{array}{c}\text { Activation } \\
\text { energy, } \mathrm{E}_{\mathrm{i}}(\mathrm{kcal} / \mathrm{mol})\end{array}$ & $\begin{array}{c}\text { Heat release, } \\
\overline{\mathrm{h}}_{\mathrm{i}}(\mathrm{kcal} / \mathrm{mol})\end{array}$ \\
\hline$\overline{\mathrm{k}}_{1}\left(\mathrm{~s}^{-1}\right)=\mathrm{A}_{1} \mathrm{~N}_{0} \exp \left(-\mathrm{E}_{1} / \mathrm{R} \overline{\mathrm{T}}\right)$ & $1.6 \mathrm{E} 10$ & 24 & 0 \\
$\overline{\mathrm{k}}_{2}\left(\mathrm{~cm}^{3} / \mathrm{m} \cdot \mathrm{s}\right)=\mathrm{A}_{2} \exp \left(-\mathrm{E}_{2} / \mathrm{R} \overline{\mathrm{T}}\right)$ & $3.7 \mathrm{E} 12$ & 25 & 92 \\
$\overline{\mathrm{k}}_{3}\left(\mathrm{~s}^{-1}\right)=\mathrm{A}_{3} \mathrm{~N}_{0} \exp \left(-\mathrm{E}_{3} / \mathrm{R} \overline{\mathrm{T}}\right)$ & $1.38 \mathrm{E} 8$ & 7 & 4 \\
$\overline{\mathrm{k}}_{4}\left(\mathrm{~s}^{-1}\right)=\mathrm{A}_{4} \mathrm{~N}_{0} \exp \left(-\mathrm{E}_{4} / \mathrm{R} \overline{\mathrm{T}}\right)$ & $7.8 \mathrm{E} 10$ & 16 & 20 \\
$\overline{\mathrm{k}}_{5}\left(\mathrm{~s}^{-1}\right)=\mathrm{A}_{5} \mathrm{~N}_{0}^{1 / 2} / \mathrm{d}$ & $3.3 \mathrm{E} 3$ & 0 & 0 \\
\hline
\end{tabular}


Assuming constant thermophysical properties, the energy equation including heat conduction can be expressed in the form:

$$
\rho c_{\mathrm{p}} \frac{\partial \overline{\mathrm{T}}}{\partial \overline{\mathrm{t}}}=\overline{\mathrm{k}}_{1} \overline{\mathrm{h}}_{1} \overline{\mathrm{y}}+\left(\overline{\mathrm{k}}_{2} \overline{\mathrm{h}}_{2} \overline{\mathrm{y}}+\overline{\mathrm{k}}_{3} \overline{\mathrm{h}}_{3}+\overline{\mathrm{k}}_{4} \overline{\mathrm{h}}_{4}+\overline{\mathrm{k}}_{5} \overline{\mathrm{h}}_{5}\right) \overline{\mathrm{x}}+\mathrm{k}_{\mathrm{T}} \bar{\nabla}^{2} \overline{\mathrm{T}}
$$

where $\rho$ is the density $\left(\mathrm{mol} / \mathrm{cm}^{3}\right), \mathrm{c}_{\mathrm{p}}$ is the specific heat $(\mathrm{kcal} / \mathrm{mol} \cdot \mathrm{K}), \overline{\mathrm{T}}$ is the temperature $(\mathrm{K})$, and $\overline{\mathrm{k}}_{\mathrm{T}}$ is the thermal conductivity of the mixture $(\mathrm{kcal} / \mathrm{cm} \cdot \mathrm{K} \cdot \mathrm{s})$.

The equations can then be non-dimensionalized by introducing the following non-dimensional parameters:

$$
\begin{aligned}
\mathrm{X} & =\frac{\overline{\mathrm{x}}}{\overline{\mathrm{y}}_{\mathrm{o}}}, \quad \mathrm{Y}=\frac{\overline{\mathrm{y}}}{\overline{\mathrm{y}}_{\mathrm{o}}}, \quad \mathrm{U}=\frac{\left(\overline{\mathrm{T}}-\overline{\mathrm{T}}_{\mathrm{o}}\right)}{\overline{\mathrm{T}}_{\mathrm{o}}}, \quad \mathrm{I}=\text { length }=\frac{\overline{\mathrm{l}}}{\mathrm{d}}, \quad \nabla^{2}=\mathrm{d}^{2} \bar{\nabla}^{2}, \\
\mathrm{t} & =\frac{\overline{\mathrm{t}}}{\overline{\mathrm{t}}_{\text {diffusion }}}=\frac{\overline{\mathrm{t}}}{\left(\mathrm{d}^{2} / \mathrm{D}_{\mathrm{Y}}\right)} \\
\mathrm{k}_{\mathrm{j}(j \neq 2)} & =\frac{\overline{\mathrm{k}}_{\mathrm{j}}}{\left(\mathrm{D}_{\mathrm{Y}} / \mathrm{d}^{2}\right)}, \quad \mathrm{k}_{2}=\frac{\overline{\mathrm{k}}_{2} \overline{\mathrm{y}}_{\mathrm{o}}}{\left(\mathrm{D}_{\mathrm{Y}} / \mathrm{d}^{2}\right)}, \quad \mathrm{h}_{\mathrm{j}}=\frac{\overline{\mathrm{h}}_{\mathrm{j}} \overline{\mathrm{y}}_{\mathrm{o}}}{\overline{\mathrm{T}}_{\mathrm{o}} \mathrm{c}_{\mathrm{p}}} \quad \text { and } \quad L e=\frac{\left(\overline{\mathrm{k}}_{\mathrm{T}} / \rho \mathrm{c}_{\mathrm{p}}\right)}{\mathrm{D}_{\mathrm{Y}}}=\frac{\alpha}{\mathrm{D}_{\mathrm{Y}}}
\end{aligned}
$$

where $\bar{y}_{o}$ is the initial concentration of $\bar{y}, \bar{T}_{o}$ is the initial mixture temperature, $d$ is the characteristic diameter of the reactor, $\overline{1}$ represents distance (i.e., the linear distance in the 1-D model and the radius in the spherically symmetric model), and $\overline{\mathrm{t}}_{\text {diffusion }}$ is the diffusion time, which is based on the mass diffusivity of the parent fuel. Unlike flow reactor analyses that typically use the flow residence time to non-dimensionalize the time and the reaction rates, the diffusion time is an appropriate characteristic time for unstirred static reactor studies. forms:

The non-dimensional species and energy equations reduce to the following

$$
\begin{gathered}
\frac{\partial \mathrm{X}}{\partial \mathrm{t}}=\mathrm{k}_{1} \mathrm{Y}+\mathrm{k}_{2} \mathrm{XY}-\left(-\mathrm{k}_{3}+\mathrm{k}_{4}+\mathrm{k}_{5}\right) \mathrm{X}+\left(\frac{\mathrm{D}_{\mathrm{X}}}{\mathrm{D}_{\mathrm{Y}}}\right) \nabla^{2} \mathrm{X} \\
\frac{\partial \mathrm{Y}}{\partial \mathrm{t}}=-\mathrm{k}_{1} \mathrm{Y}-\mathrm{k}_{2} \mathrm{XY}+\nabla^{2} \mathrm{Y} \\
\frac{\partial \mathrm{U}}{\partial \mathrm{t}}=\mathrm{k}_{1} \mathrm{~h}_{1} \mathrm{Y}+\left(\mathrm{k}_{2} \mathrm{~h}_{2} \mathrm{Y}+\mathrm{k}_{3} \mathrm{~h}_{3}+\mathrm{k}_{4} \mathrm{~h}_{4}+\mathrm{k}_{5} \mathrm{~h}_{5}\right) \mathrm{X}+\mathrm{Le} \nabla^{2} \mathrm{U}
\end{gathered}
$$

where the two non-dimensional parameters in the species and energy equations are: (1) the ratio of the mass diffusivities of species $x$ and $y$, i.e., $\left(\frac{D_{x}}{D_{Y}}\right)$, and (2) the Le defined as the thermal diffusivity of the mixture relative to the mass diffusivity of species $y$. 


\section{RESULTS}

\section{One-Dimensional Model Results}

The coupled species and energy equations were solved in a one-dimensional domain of length $\mathrm{d}$ such that $0 \leq 1 \leq 1$. The domain was uniformly meshed with 808 elements with a maximum element size equal to 0.01 . No flux boundary conditions were applied to the temperature and species concentrations at $1=0$, i.e., $\nabla \mathrm{U}=0 ; \nabla \mathrm{X}=\nabla \mathrm{Y}=0$. At $\mathrm{I}=1$, no species fluxes, i.e., a chemically inert boundary $(\nabla \mathrm{X}=\nabla \mathrm{Y}=0)$, and a fixed gas temperature equal to the initial temperature $(\mathrm{U}=0)$ were assumed. The mixture composition was assumed to be $\bar{y}_{0}$ initially and the initial temperature everywhere in the domain is taken to be $\bar{T}_{0}$, so that the initial conditions were taken to be $\mathrm{Y}=1, \mathrm{X}=0$, and $\mathrm{U}=0$. The parent fuelair mixture was further assumed to be equimolar such that $\bar{y}_{\mathrm{o}}=\mathrm{N}_{\mathrm{o}} / 2=$ $\overline{\mathrm{P}}_{\mathrm{o}} / 2 \mathrm{R} \overline{\mathrm{T}}_{\mathrm{o}}$. The characteristic size of the reactor (d) was taken to be $3 \mathrm{~cm}$ and $\mathrm{D}_{\mathrm{Y}}$ was assumed constant and estimated to be $0.8 \mathrm{~cm}^{2} / \mathrm{s}$, which is the binary diffusion coefficient for $\mathrm{n}-\mathrm{C}_{4} \mathrm{H}_{10}$ into an equimolar $\mathrm{n}-\mathrm{C}_{4} \mathrm{H}_{10}+\mathrm{O}_{2}$ premixture at $600 \mathrm{~K}$ and $50.7 \mathrm{kPa}$.

The coupled partial differential equations were integrated using the PDE solver, UMFPACK (Davis, 2004). The time-step was variable. The relative and absolute tolerances on the non-dimensional temperature and species concentrations were $10^{-6}$ and the maximum backwards differentiation order was 5 . For a fixed ratio of mass diffusivities, the Le was varied from 0.1 to 3 for pressures ranging from 25 to $95 \mathrm{kPa}$ and temperatures in the range of 540 to $660 \mathrm{~K}$ were considered. From the computed temperature and species profiles, ignition diagrams were developed and are shown in Figures 1a-d for Le's equal to (a) 0.1, (b) 0.5, (c) 1.0, and (d) 3.0.

For Le's equal to $0.1,0.5$, and 1.0 , the model predicts slow reaction and singlestage ignition with a general shift in the slow reaction - ignition stability boundary towards higher temperatures and pressures with increasing Le. For $\mathrm{Le}=3.0$, damped oscillatory cool flames characterized by a weak temperature rise on the order of $\mathrm{U} \approx 0.2$ were predicted for pressures ranging from 67 to $80 \mathrm{kPa}$ and temperatures ranging from 610 to $650 \mathrm{~K}$. Additionally, two-stage ignitions were predicted at $80 \mathrm{kPa}$ for $\overline{\mathrm{T}}_{\mathrm{o}}=590 \mathrm{~K}, 610 \mathrm{~K}$, and $630 \mathrm{~K}$, conditions for which the model predicts single-stage ignitions at lower Le's. Clearly, the predictions suggest that increasing Le promotes cool flames and two-stage ignitions.

For representative cool flames conditions $\left(\overline{\mathrm{P}}_{\mathrm{o}}=67 \mathrm{kPa}, \overline{\mathrm{T}}_{\mathrm{o}}=630 \mathrm{~K}\right), \mathrm{U}(1=0, \mathrm{t})$ is plotted in Figure 2a followed by the temperature, $U(1, t)$, and the species concentration distributions, $X(1, t)$ and $Y(1, t)$, in Figures $2 b-2 d$ for $t \leq 1$. $U(I=0, t)$ initially increases, reaches a peak value of 0.12 and then decreases as the reaction self-arrests and cools. The spatial temperature profile that develops is approximately parabolic with the maximum temperature occurring at the center, which increases until $\mathrm{t}=0.8$ and then subsequently decreases. The distribution of fuel also decreases nearly uniformly for $\mathrm{t}<0.5$ and then decreases at an accelerated rate in the higher temperature region (central region). Coincident with the consumption of $\mathrm{Y}$, the $\mathrm{X}$ concentration also increases uniformly for $t \leq 0.5$, and is then decreases, most rapidly in the high temperature region.

At the same temperature and slightly higher pressure $\left(\overline{\mathrm{P}}_{\mathrm{o}}=80 \mathrm{kPa}\right.$, $\overline{\mathrm{T}}_{\mathrm{o}}=630 \mathrm{~K}$ ), transition to ignition occurs as shown in Figures 3a-3e. Specifically, 


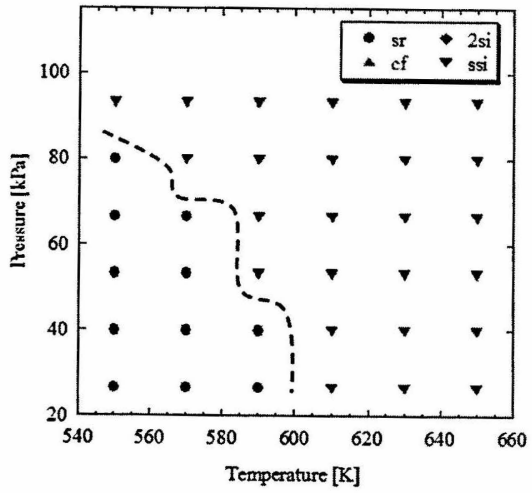

(a)

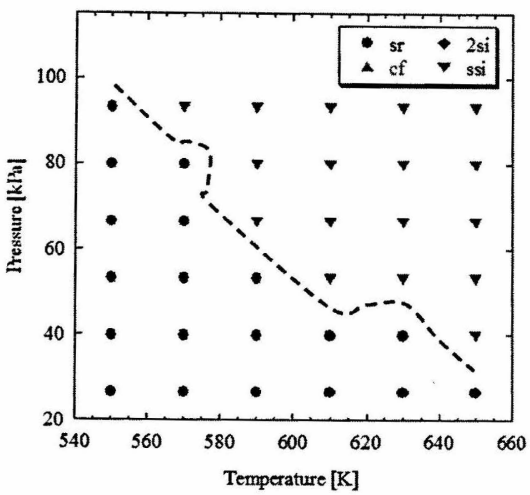

(c)

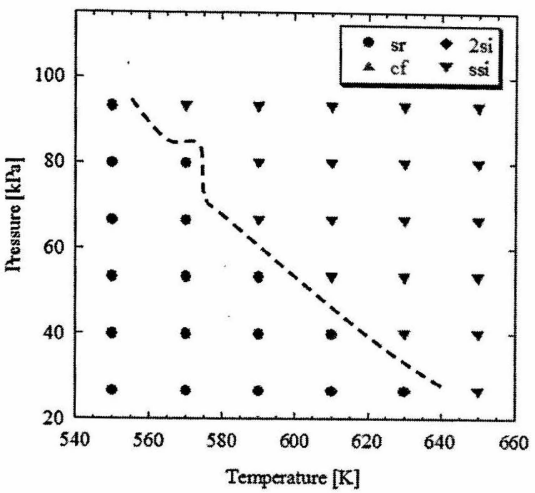

(b)

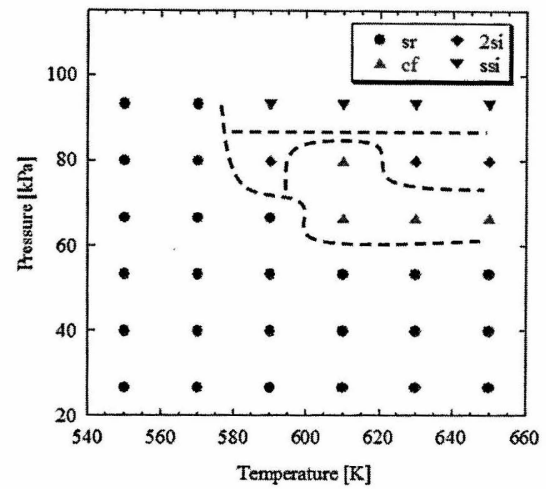

(d)

Figure 1 Predicted ignition diagrams for different $\mathrm{Le}=$ (a) 0.1 , (b) 0.5 , (c) 1.0 , (d) $3.0 ; \mathrm{D}_{\mathrm{Y}} / \mathrm{D}_{\mathrm{X}}=0.2$. Dashed lines highlight the stability boundaries $(\mathrm{sr}=$ slow reaction, $2 \mathrm{si}=$ two-stage ignition, $\mathrm{cf}=\mathrm{cool}$ flame, ssi = single-stage ignition).

$\mathrm{U}(\mathrm{I}=0, \mathrm{t})$ and $\mathrm{U}(\mathrm{I}, \mathrm{t})$ are plotted in Figures $3 \mathrm{a}$ and $3 \mathrm{~b}$, respectively, and show a modest temperature rise, followed by transition to ignition. The $Y(1, t)$ distribution is then shown in Figure 3c. As observed at lower pressure, Y initially decreases nearly uniformly for modest temperature increases, then is consumed completely during ignition at $\mathrm{t} \approx 0.785$. Similarly, Figure $3 \mathrm{~d}$ shows $\mathrm{X}(1, \mathrm{t})$, which initially increases uniformly owing to low-temperature branching, decreases in the high-temperature region, then increases again in the high-temperature region due to high-temperature branching prior to complete consumption during ignition. To further clarify the oscillatory $\mathrm{X}$ concentration, Figure $3 \mathrm{e}$ shows both $\mathrm{X}$ and $\mathrm{U}$ at $\mathrm{I}=0$ as a function of time.

Note that in all cases reported, the ratio of the diffusivity of the parent fuel to that associated with the autocatalytic species $\left(D_{Y} / D_{X}\right)$ was 0.2 . To determine the sensitivity of the results to $D_{Y} / D_{X}$, numerical exercises were conducted by varying the ratio between 0.2 to 1.0 for unity Le. For these cases, the induction times and the magnitudes of the temperature and the species concentrations varied, yet the 


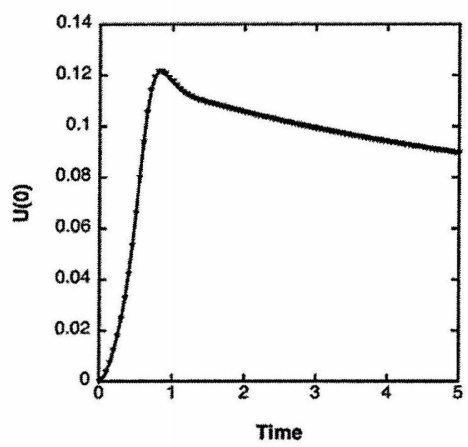

(a)

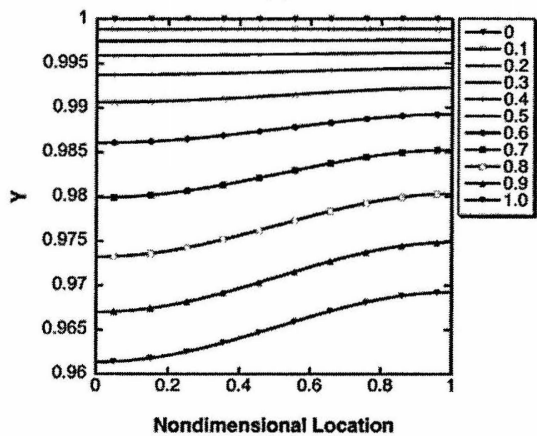

(c)

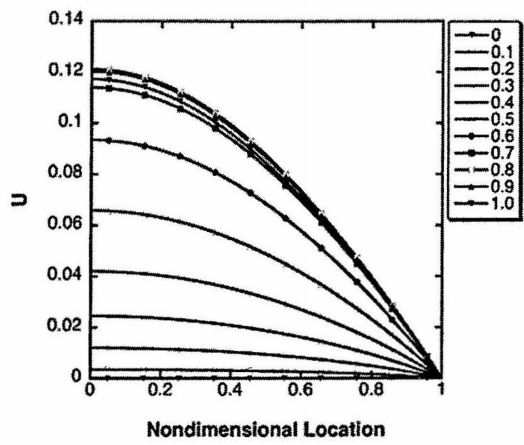

(b)

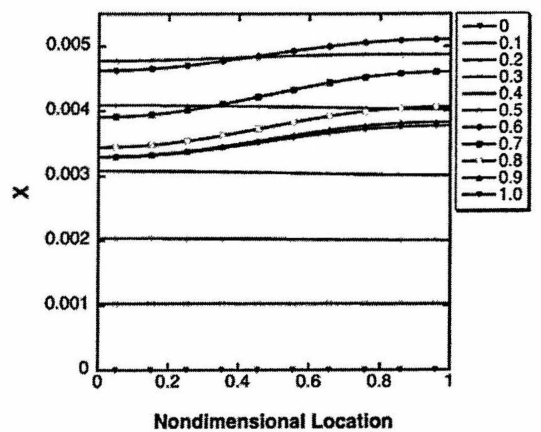

(d)

Figure 2 The temperature and species concentration distributions for a representative cool flame reaction $\left(\overline{\mathrm{P}}_{\mathrm{o}}=67 \mathrm{kPa}, \overline{\mathrm{T}}_{\mathrm{o}}=630 \mathrm{~K}, \mathrm{D}_{\mathrm{Y}} / \mathrm{D}_{\mathrm{X}}=0.2, \mathrm{Le}=3\right)$. Figure (a) represents the temperature distribution at $1=0, U(1=0, t)$, as a function of nondimensional time and (b)-(d) represent the $U(1, t), Y(1, t)$, and $\mathrm{X}(\mathrm{l}, \mathrm{t})$ profiles at different nondimensional times (shown in the legend).

ignition diagrams were found to be insensitive to $D_{Y} / D_{X}$ and remained the same as that shown in Figure 1c.

\section{Spherical Model Results}

Assuming spherical symmetry, the model was also solved on a twodimensional, axisymmetric half-domain assuming no flux boundary conditions for the species concentrations and a fixed temperature $(U=0)$ at the outer wall. Along the symmetry axis, no heat or species fluxes were assumed. The two-dimensional domain was meshed with 11,167 triangular elements of which 313 were boundary elements. As before, the radial distance was non-dimensionalized by the radius of the vessel, such that the non-dimensional radius ranged from 0 to 1.0.

The corresponding ignition diagram based on the results from the 2-D model for unity Le is shown in Figure 4. Cool flames and two-stage ignitions are predicted between 600 to $650 \mathrm{~K}$ and 63 to $82 \mathrm{kPa}$, which were predicted by the 1-D model at higher Le. Note also that the stability boundaries shift to higher temperatures and pressures in the spherical model as compared to the 1-D model.

The temperature and species concentration distributions are shown in Figure 5 for a representative damped oscillatory cool flame. Figure 5a shows $\mathrm{U}(1=0, t)$ 


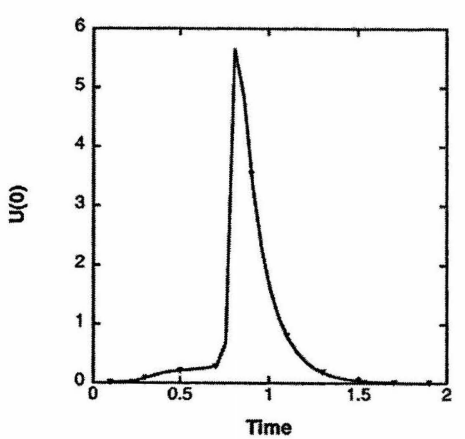

(a)

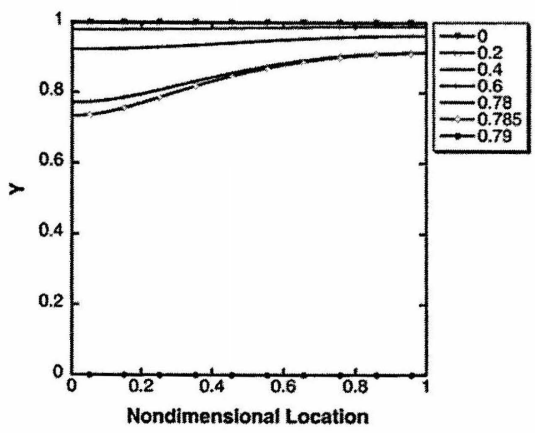

(c)

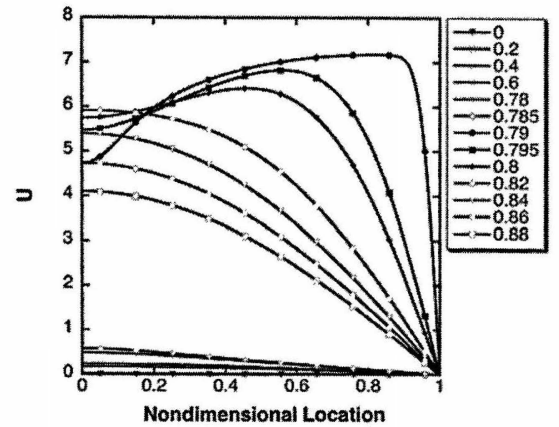

(b)

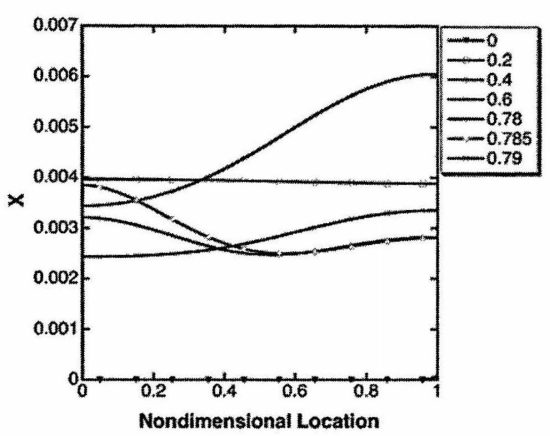

(d)

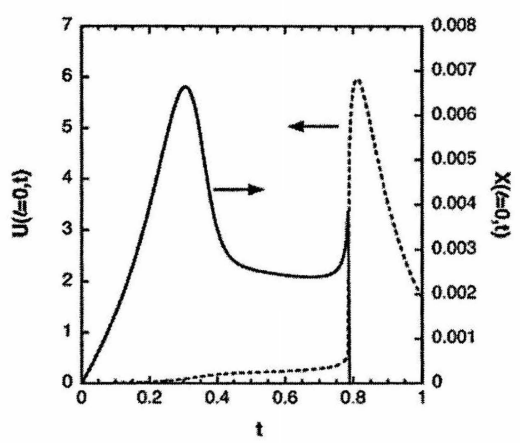

(e)

Figure 3 The non-dimensional temperature and species concentration distributions for a representative twostage ignition $\left(\overline{\mathrm{P}}_{\mathrm{o}}=80 \mathrm{kPa}, \overline{\mathrm{T}}_{\mathrm{o}}=630 \mathrm{~K}, \mathrm{D}_{\mathrm{Y}} / \mathrm{D}_{\mathrm{X}}=0.2, \mathrm{Le}=3\right)$. Figure (a) shows the temperature distribution at $1=0$ as a function of time, $U(1=0, t)$, and $(b)-(d)$ represent the $U(1, t), Y(1, t)$, and $X(1, t)$ profiles at different times; $(e) U(1=0, t)$ (dashed line) and $\mathrm{X}(\mathrm{I}=0, \mathrm{t})$ (solid line) as a function of time at $1=0$.

initially increases to a maximum value of 0.34 , then continues as a damped oscillation. As observed in other models and in the 1-D case considered above, the spatial temperature profile (Figure $5 \mathrm{~b}$ ) that develops is approximately parabolic, and increases until $\mathrm{t}=1.05$, then decreases as the reaction conductively cools. Figure $5 \mathrm{c}$ shows the corresponding fuel concentration. Initially, $\mathrm{Y}$ decreases rapidly in the 


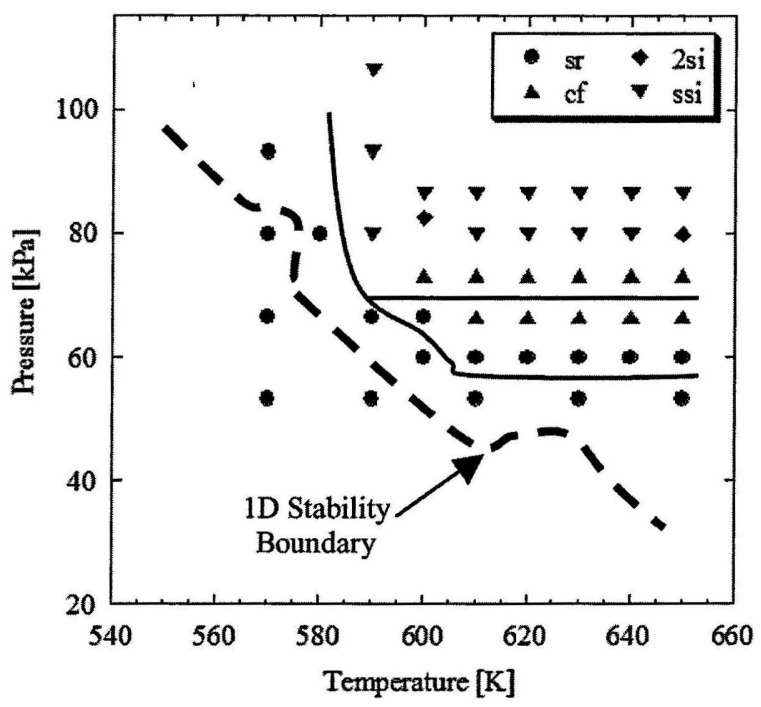

Figure 4 Predicted ignition diagram for $\mathrm{Le}=1.0$ and $\mathrm{D}_{\mathrm{Y}} / \mathrm{D}_{\mathrm{X}}=0.2$ using the spherical, axi-symmetric model. The stability boundary determined from the $1-\mathrm{D}$ model is indicated by the bold, dashed line as shown in Figure1c.

high temperature region, then increases in the high-temperature region, rather than decreases for $1.1 \leq \mathrm{t} \leq 1.4$, as it diffuses radially inwardly from the cooler outer regions $(0.3<1 \leq 1)$. At later times $(\mathrm{t}>1.4)$, $\mathrm{Y}$ decreases nearly uniformly. The corresponding concentration of $\mathrm{X}$ is shown in Figure $5 \mathrm{~d}$, which oscillates, with higher concentrations formed in cooler regions.

The temperature distribution associated with a representative two-stage ignition is shown in Figures $6 \mathrm{a}$ and $6 \mathrm{~b}$ highlighting the pre-ignition $(\mathrm{t} \leq 0.831)$ and post-ignition periods $(t \geq 0.832)$. In the early stages, the temperature profile is approximately parabolic before developing a steep gradient characteristic of an ignition front at $t=0.832$, which then propagates radially outward. The gas then cools via conduction to the wall. The corresponding concentration distributions are shown in Figures 6c and 6d. Initially, the fuel is partially consumed throughout the domain, albeit faster in the higher temperature central region, and then is completely consumed at ignition. $\mathrm{X}$ initially increases uniformly throughout the reactor $(\mathrm{t} \leq 0.6 \mathrm{~s})$ due to low-temperature branching. It then develops non-uniformly as $\mathrm{X}$ decreases at small radii and increases at large radii $(t=0.8)$ as the temperature continues to increase within the low-temperature regime. At $t=0.831$, the trend reverses and $\mathrm{X}$ increases at small radii and decreases at large radii forming a "saddle-shaped" distribution as the mechanism transitions to high-temperature branching. At ignition $(\mathrm{t}=0.832)$, a well-defined front develops and propagates radially outward, completely consuming the reactants and ending the production of $\mathrm{X}$.

\section{DISCUSSION}

The Wang-Mou 1-D model suggests that increasing Le promotes damped oscillatory cool flames, which is consistent with the Le dependence reported in the 


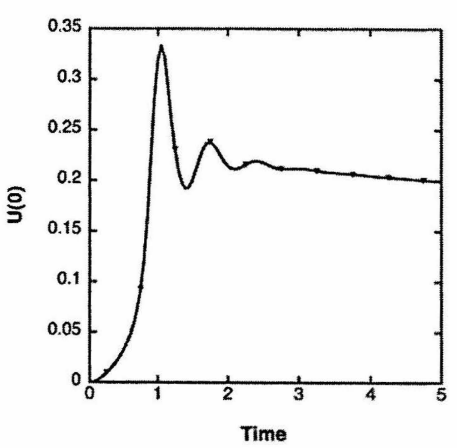

(a)

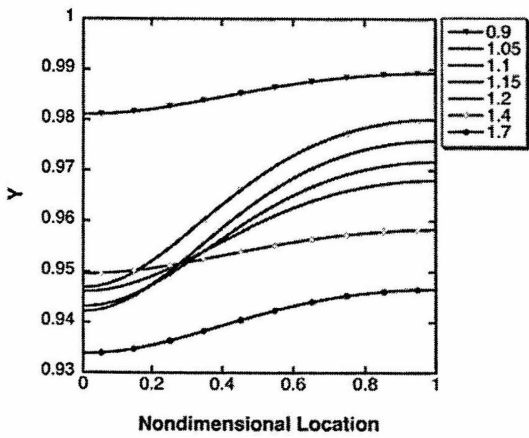

(c)

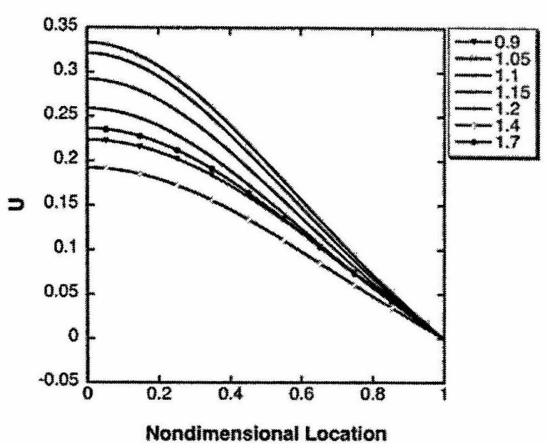

(b)

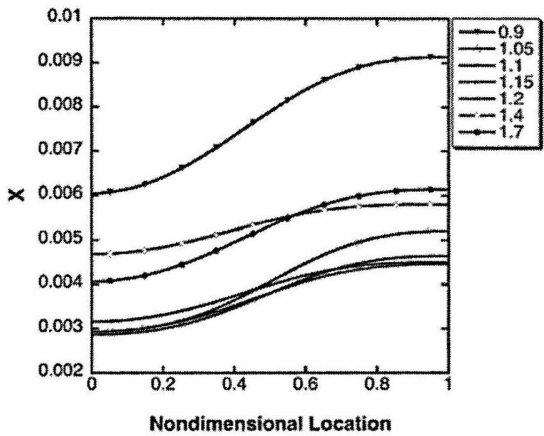

(d)

Figure 5 The temperature and species concentration distributions for a representative cool flame predicted by spherical model $\left(\bar{T}_{0}=610 \mathrm{~K}, \overline{\mathrm{P}}_{0}=73 \mathrm{kPa}, \mathrm{D}_{\mathrm{Y}} / \mathrm{D}_{\mathrm{X}}=0.2, \mathrm{Le}=1\right)$. Figure $5 \mathrm{a}$ represents the temperature distribution at $\mathrm{I}=0$ as a function of time, $U(I=0, t)$, and (b)-(d) represent the $U(I, t), Y(I, t)$, and $\mathrm{X}(1, \mathrm{t})$ profiles at different times for $\mathrm{t} \leq 1.7$.

numerical studies performed with the Gray-Yang model (Fairlie et al., 2000). Additionally, the Wang-Mou model captures the onset of the two-stage ignition due to the high temperature branching step, and also suggests that two-stage ignition is promoted by increasing Le.

Diffusive effects are highlighted throughout the predicted increase in the fuel concentration in the innermost region of the reactor during a damped oscillatory cool flame since the chemical reaction time at low temperatures is long relative to the diffusion time.

\section{CONCLUSIONS}

A reactive-diffusive model was developed based on the Wang-Mou global kinetic scheme and used to compute the spatio-temporal temperature, fuel concentration and autocatalytic chain carrier species concentrations for different Le's and species diffusivities. Increasing Le was shown to promote cool flame oscillations and two-stage ignition, while the ratio of $\mathrm{D}_{\mathrm{Y}} / \mathrm{D}_{\mathrm{X}}$ had no effect on the ignition diagrams for $0.2 \leq \mathrm{D}_{\mathrm{Y}} / \mathrm{D}_{\mathrm{X}} \leq 1$. 


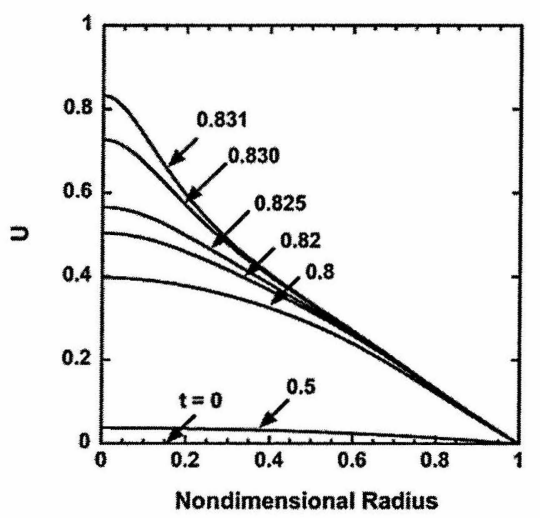

(a)

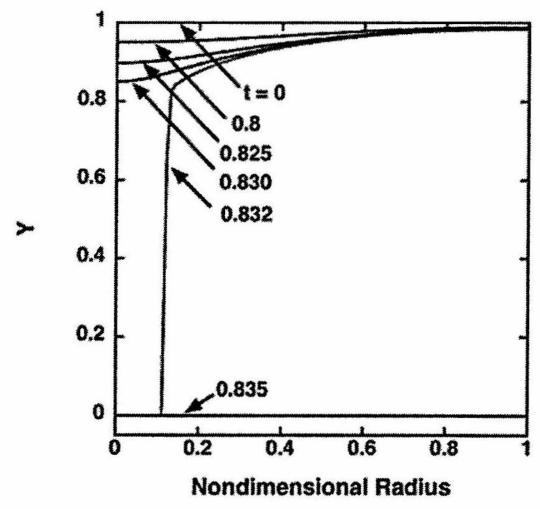

(c)

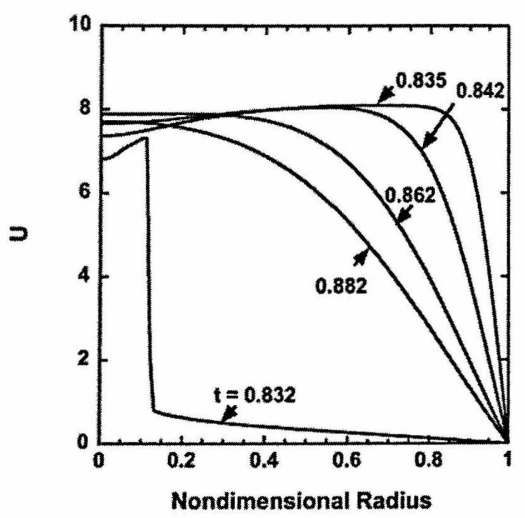

(b)

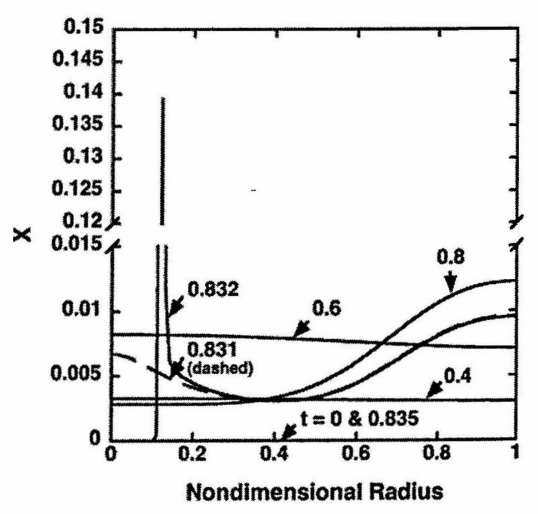

(d)

Figure 6 The temperature and species concentration distributions for a representative two-stage ignition $\left(\overline{\mathrm{T}}_{0}=600 \mathrm{~K}, \overline{\mathrm{P}}_{0}=83 \mathrm{kPa}, \mathrm{D}_{\mathrm{Y}} / \mathrm{D}_{\mathrm{X}}=0.2, \mathrm{Le}=1\right)$. Figures $(\mathrm{a})$ and $(\mathrm{b})$ show $\mathrm{U}(1, \mathrm{t})$ before and after ignition. Figures (c) and (d) are the $\mathrm{Y}(\mathrm{l}, \mathrm{t})$, and $\mathrm{X}(\mathrm{l}, \mathrm{t})$ distributions, respectively.

Extending the model to a spherically-symmetric domain, the stability boundary shifted to higher temperatures and pressures relative to the 1-D case. Moreover, the spherical model predicted cool flames and two-stage ignitions at unity Le, which were only captured by the $1-\mathrm{D}$ model at higher Le's.

\section{NOMENCLATURE}

x Parent fuel + oxidizer

y Autocatalytic chain carrier species

$\vec{x} \quad$ Concentration of species $\mathrm{x}\left(\mathrm{mol} / \mathrm{cm}^{3}\right)$

$\bar{y} \quad$ Concentration of species y $\left(\mathrm{mol} / \mathrm{cm}^{3}\right)$

$\bar{y}_{o} \quad$ Initial concentration of species y $\left(\mathrm{mol} / \mathrm{cm}^{3}\right)$

$\mathrm{X}$ Non-dimensional concentration of species $\mathrm{x}$

$\mathrm{Y}$ Non-dimensional concentration of species $\mathrm{y}$

$\mathrm{S}_{1,2} \quad$ Terminal product species

$\mathrm{D}_{\mathrm{Y}}$ Mass diffusivity of species y $\left(\mathrm{cm}^{2} / \mathrm{s}\right)$ 
$\mathrm{D}_{\mathrm{X}} \quad$ Mass diffusivity of species $\mathrm{x}\left(\mathrm{cm}^{2} / \mathrm{s}\right)$

$\overline{\mathrm{k}}_{\mathrm{T}} \quad$ Thermal conductivity of the mixture $(\mathrm{kcal} / \mathrm{cm} \cdot \mathrm{K} \cdot \mathrm{s})$.

Le Non-dimensional ratio of the thermal conductivity of the mixture to mass

diffusivity of species $y=\alpha / D_{Y}$

$\alpha \quad$ Thermal diffusivity of the mixture $=\overline{\mathrm{k}}_{\mathrm{T}} / \rho \mathrm{c}_{\mathrm{p}}$

$\overline{\mathrm{k}}_{\mathrm{i}} \quad$ Reaction rates of steps 1-5 (given in Table 1)

$\mathrm{k}_{\mathrm{i}} \quad$ Non-dimensional reaction rates of steps $1-5$

$\overline{\mathrm{h}}_{\mathrm{i}} \quad$ Heat release of steps $1-5(\mathrm{kcal} / \mathrm{mol})$

$\mathrm{h}_{\mathrm{i}} \quad$ Non-dimensional heat release of steps 1-5

$\overline{\mathrm{T}}$ Temperature (K)

$\overline{\mathrm{T}}_{\mathrm{o}} \quad$ Initial gas temperature (K)

$\mathrm{U} \quad$ Non-dimensional temperature $=\left(\overline{\mathrm{T}}-\overline{\mathrm{T}}_{\mathrm{o}}\right) / \overline{\mathrm{T}}_{\mathrm{o}}$

$\overline{\mathrm{t}} \quad$ Time (s)

t Non-dimensional time

$\overline{1} \quad$ Dimensional length $(\mathrm{cm})$

d Reactor size (cm)

1 Non-dimensional length

$\mathrm{E}_{\mathrm{i}} \quad$ Activation energies for steps $1-5(\mathrm{kcal} / \mathrm{mol})$

$\mathrm{A}_{\mathrm{i}} \quad$ Pre-exponential factors

$\mathrm{N}_{0} \quad$ Initial reactant concentration $\left(\mathrm{mol} / \mathrm{cm}^{3}\right)$

$\mathrm{R} \quad$ Ideal gas constant

$\mathrm{c}_{\mathrm{p}} \quad$ Specific heat $(\mathrm{kcal} / \mathrm{mol} \cdot \mathrm{K})$

$\overline{\mathrm{P}}_{\mathrm{o}} \quad$ Initial gas pressure $(\mathrm{kPa})$

\section{REFERENCES}

Barnard, J. and Harwood, B. (1974) Physical factors in the study of the spontaneous ignition of hydrocarbons in static systems. Combust. Flame, 22(1), 35-42.

Campbell, A., Cardoso, S., and Hayhurst, A. (2006) The behaviour of salnikov's reaction, $\mathrm{P} \rightarrow \mathrm{A} \rightarrow \mathrm{B}$, in a spherical batch reactor with the diffusion of heat and matter. Phys. Chem. Chem. Phys., 8, 2866-2878.

Cardoso, S., Kan, P., Savjani, K., Hayhurst, A., and Griffiths, J. (2004a) The effect of natural convection on the gas-phase Sal'nikov reaction in a closed vessel. Phys. Chem. Chem. Phys., 6, 1687-1696.

Cardoso, S., Kan, P., Savjani, K., Hayhurst, A., and Griffiths, J. (2004b) Combust. Flame, 136, 241-245.

Davis, T. (2004) Algorithm 832: UMFPACK V4.3-an unsymmetric-pattern multifrontal method. ACM Transactions on Math. Soft., 30(2), 196-199.

Fairlie, R., Griffiths, J., and Pearlman, H. (2000) A numerical study of cool flame development under microgravity. Proc. Combust. Instit., 28(2), 1693-1700.

Fairlie, R., Griffiths, J., Hughes, K., and Pearlman, H. (2004) Cool flames in space: Experimental and numerical studies of propane combustion. Proc. Combust. Instit., 30, 10571064.

Foster, M. and Pearlman, H. (2006) Cool flames at terrestrial, partial, and near-zero gravity. Combust. Flame, 147(1-2), 108-117.

Liang, C., Mou, C., and Lee, D. (2003) Dynamic behavior and sensitivity of skeleton thermokinetic model for acetaldehyde oxidation. Chem. Eng. Sci., 58, 4173-4184.

Pearlman, H. (2000) Low-temperature oxidation reactions and cool flames at earth and reduced gravity. Combust. Flame, 121(1-2), 390-393.

Pearlman, H. and Foster, M. (2008) The role of diffusive transport on low and intermediate temperature hydrocarbon oxidation: Closed reactor experiments using equimolar 
n- $\mathrm{C}_{4} \mathrm{H}_{10}+\mathrm{O}_{2}$ premixtures at reduced-gravity. Combust. Sci. and Technol, 180(2), in press.

Wang, X. and Mou, C. (1985) A thermokinetic model of complex oscillations in gaseous hydrocarbon oxidation. J. Chem. Phys., 83(9), 4554-4561.

Yang, C. and Gray, B. (1969a) Slow oxidation of hydrocarbons and cool flames. J. Phjs. Chem., 73, 3395-3406.

Yang, C. and Gray, B. (1969b) Unified theory of explosions, cool flames and two-stage ignitions. Trans. Farad. Soc., 65(558), 1614-1622. 

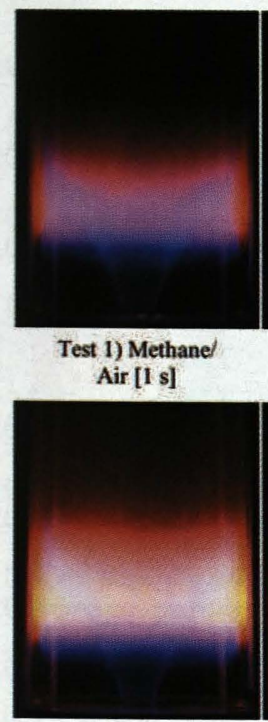

5) Methanel $30 \% \mathrm{O}_{2}-\mathrm{CO}_{2}$ [1 s]

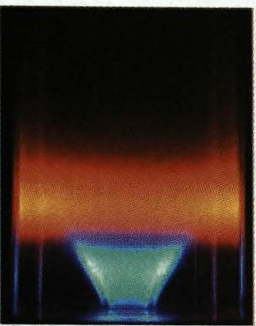

2) Slurry-feed syngas/Air $[0.25 \mathrm{~s}]$

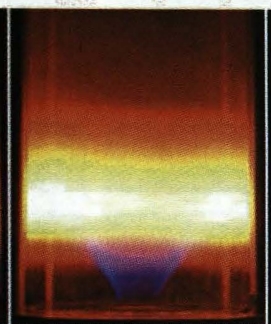

6) Methane/ $34 \% \mathrm{O}_{2}-\mathrm{CO}_{2}[0.25 \mathrm{~s}]$

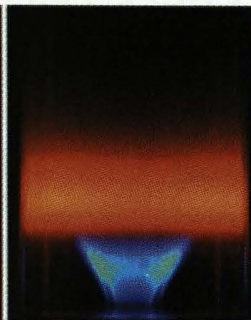

3) Dry-feed syngas/ Air [0.05 s]

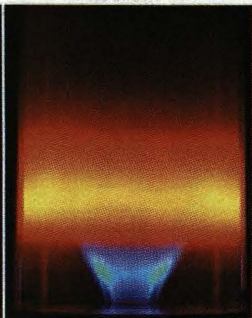

7) Slurry-feed syngas/ $30 \% \mathrm{O}_{2}-\mathrm{CO}_{2}[0.05 \mathrm{~s}]$

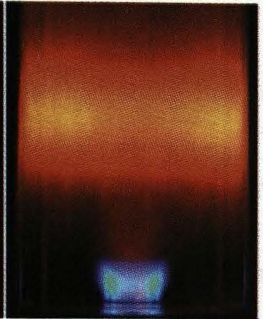

4) $\mathrm{H}_{2}$-rich syngas' Air [2 s]

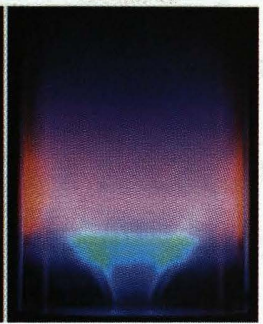

9) $\mathrm{H}_{2}$-lean syngas! $30 \% \mathrm{O}_{2}-\mathrm{CO}_{2}[0.05 \mathrm{~s}]$

Color Plate 1 Photographs of the methane and syngas flames with the combustor operating at an equivalence ratio of 0.7 . The inlet annulus is at the bottom center of each image - see Figure 5. The pink and red-orange glow originates from surface thermal emission where the flame gases impinge on the quartz cylinder that surrounds the flame. The camera exposure time of each image is indicated in the square brackets. (See Figure 4, p. 73).
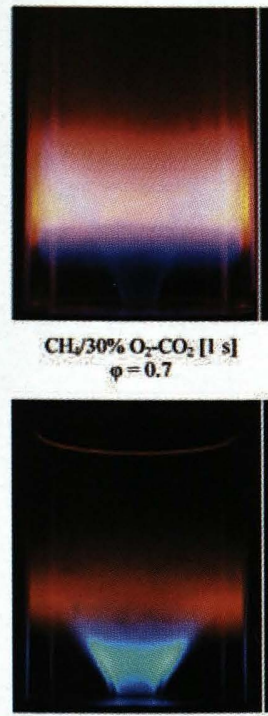

Slurry-feed syngas/ $25 \% \mathrm{O}_{2}-\mathrm{CO}_{2}[0.05 \mathrm{~s}]$

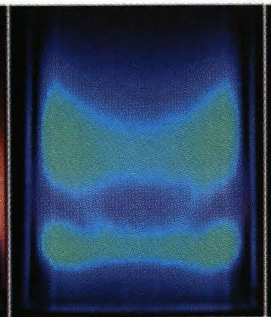

$\mathrm{CH}_{4} / 30 \% \mathrm{O}_{2}-\mathrm{CO}_{2}[4 \mathrm{~s}]$ $\varphi=0.65$

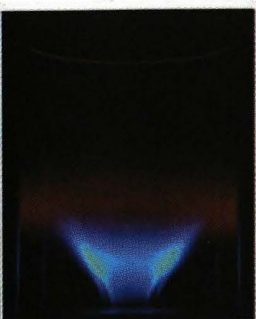

Slurry-feed syngas/ $20 \% \mathrm{O}_{2}-\mathrm{CO}_{2}[0.05 \mathrm{~s}]$

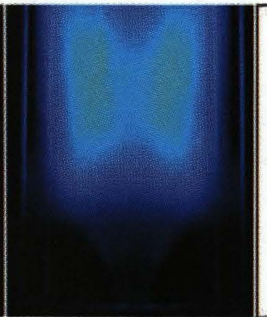

$\mathrm{CH}_{4} / 30 \% \mathrm{O}_{2}-\mathrm{CO}_{2}[4 \mathrm{~s}]$ $\varphi=0.58$

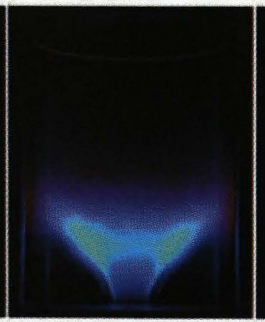

Slurry-feed syngas/ $15 \% \mathrm{O}_{2}-\mathrm{CO}_{2}[0.25 \mathrm{~s}]$

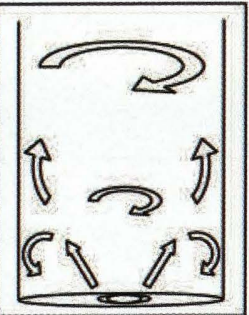

Outline of combustion chamber and annulus

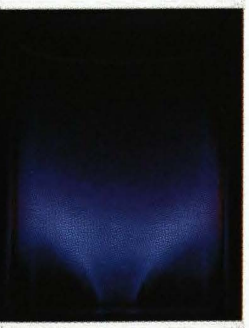

Slurry-feed syngas $13 \% \mathrm{O}_{2}-\mathrm{CO}_{2}[0.25 \mathrm{~s}]$

Color Plate 2 Top: photographs of the methane $/ 30 \% \mathrm{O}_{2}-\mathrm{CO}_{2}$ flame over a range of equivalence ratios $(\varphi)$. Bottom: photographs of the slurry-feed $/ \mathrm{O}_{2}-\mathrm{CO}_{2}$ flames operating over a range of oxygen concentrations for $\varphi=0.95$. The schematic illustrates the location of the inlet annulus, the walls of the combustion chamber, and the primary flow directions within the combustor. The camera exposure time of each image is indicated in the square brackets. (See Figure 5, p. 74). 


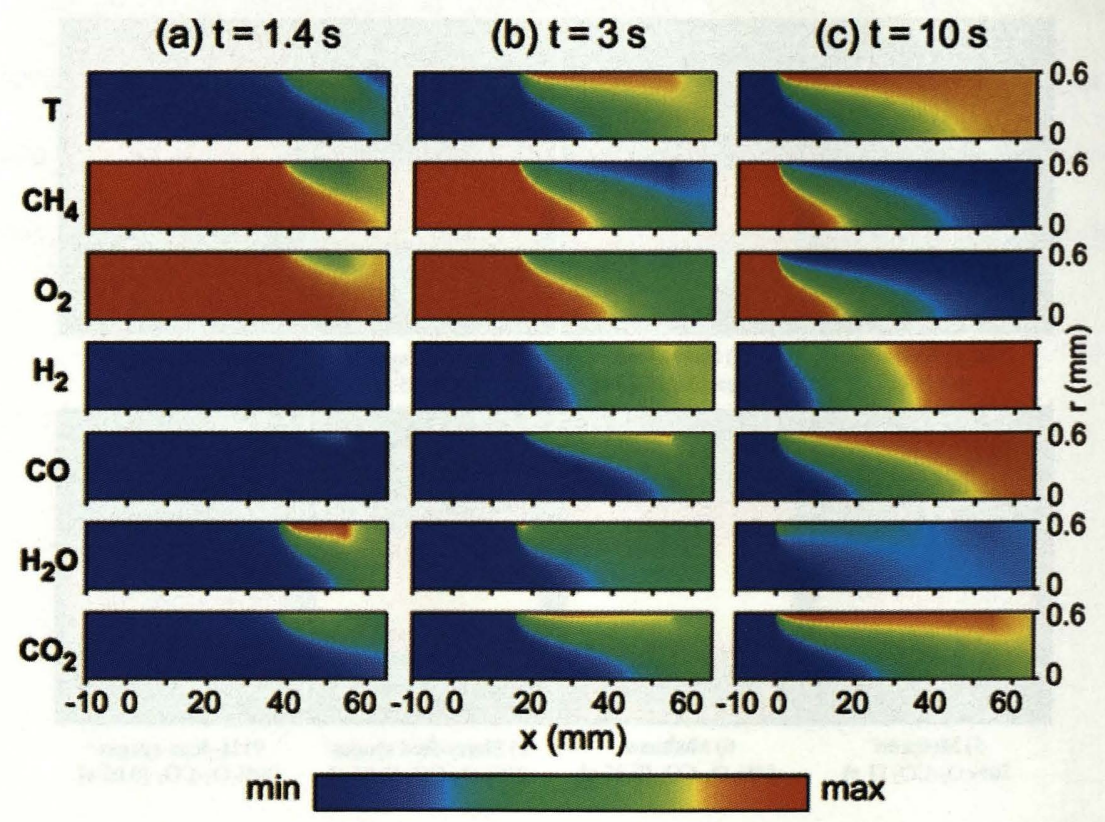

Color Plate 3 Predicted 2-D distributions of temperature and species mass fractions for Case 1 at three times: (a) $1.4 \mathrm{~s}$, (b) $3.0 \mathrm{~s}$, and (c) $10.0 \mathrm{~s}$. The maximum and minimum levels of the color bar are: T: $681 \mathrm{~K}$ to $1146 \mathrm{~K}, \mathrm{CH}_{4}: 0.039$ to $0.131, \mathrm{O}_{2}: 0.0$ to $0.131, \mathrm{H}_{2}: 0.0$ to $0.0186, \mathrm{CO}: 0.0$ to $0.123, \mathrm{H}_{2} \mathrm{O}: 0.332$ to 0.398 , and $\mathrm{CO}_{2}: 0.406$ to 0.478 . The centerline is at $r=0$ and the gas-solid interface at $r=0.6 \mathrm{~mm}$. The catalytically active part of the reactor extents over $0 \leq x \leq 55 \mathrm{~mm}$. (See Figure 4, p. 105). 